\title{
El sonido del odio como arma política de la extrema derecha española
}

\author{
Eva Gómez Fernández \\ evagomezfer22@gmail.com \\ Universidad de Cantabria
}

Resumen

El artículo aborda el impacto que tuvo el género musical Rock. Against Communism en España durante los años noventa. Así, se describirá la politización del rock en Reino Unido e Italia porque fueron los principales exportadores del RAC. Finalmente, se analizarán los grupos pioneros de este estilo musical porque sus integrantes militaron en asociaciones de extrema derecha y, con sus canciones, captaron a militantes skinheads neonazis. Con sus letras, un informe Raxen y fuentes secundarias de la hemeroteca se ha destacado que Barcelona, Madrid y Valencia fueron los núcleos principales donde se desarrolló el RAC.

\section{Palabras Clave}

Música, Rock Against Communism, skinheads, España, extrema derecha, violencia 


\title{
The sound of hate as a political weapon of the Spanish extreme right
}

\begin{abstract}
The article addresses the impact that the Rock. Against Communism musical genre had in Spain during the 1990s. Thus, the politicization of rock in the United Kingdom and Italy, which were the main exporters of the RAC, will be described. Finally, the pioneer groups of this musical style will be analyzed because their members militated in extreme right-wing associations and, with their songs, they captured neo-Nazi skinhead militants. With its letters, Raxen reports and secondary sources from the newspaper library, it has been highlighted that Barcelona, Madrid and Valencia were the main centers where the RAC was developed.
\end{abstract}

\section{Keywords}

Music, Rock Against Communism, skinhead, Spain, far-right, violence

\section{Their Kingdom Will Fall: Reino Unido e Italia como núcleos exportadores del RAC}

En los años sesenta la música se convirtió en un catalizador de la juventud de izquierdas con la canción protesta, que versaba sobre el marco socio-político, y a partir de 1976, en Reino Unido, los círculos antifascistas crearon un movimiento cultural conocido como el Rock. Against Racisim (RAR) como protesta por la popularidad del National Front (NF), un partido de extrema derecha. Esta formación, impulsó, como rechazo al RAR, el Rock. Against Comunism (RAC) que, en sus inicios, eran eventos en los que tocaban varias bandas que emitían mensajes anticomunistas. El RAC se convirtió en un género musical a finales de los setenta, cuando se integró dentro del Movimiento Musical del Poder Blanco que apelaba a la internacionalización de la ultraderecha y a la defensa de la supremacía blanca (Camus \& Lebourg, 2020). Sus mensajes atrajeron a una juventud desinformada que pertenecía al movimiento skinhead. La traducción de esta palabra es "cabezarapada" en referencia al corte de su cabello. Aunque esta expresión artística atrajo a adolescentes la ultraderecha, en sus inicios esta cultura juvenil fue un fenómeno multirracial que se formó por la confluencia de inmigrantes jamaicanos y de bri-

1 Título que da nombre a una canción de Skrewdriver donde se muestra el rechazo al sistema político y se demanda la inclusión del nativismo en la agenda política. 
tánicos provenientes de áreas industriales (Casals i Meseguer, 1995). De este fenómeno surgieron cuatro corrientes: la comunista, la antifascista, la libertaria y la neonazi (Viñas i Gràcia, 2013). La última surgió en 1968 cuando Eddy Morrison, delegado del NF por Leeds, comprendió que la cosmovisión marxista del proletariado estaba en fase de deconstrucción por lo que, percatándose de que la música dominaba los espacios sociales de estos jóvenes, fundó el fanzine Punk Front para promocionar el RAC e incentivó la creación de las bandas The Dentist y The Ventz que estuvieron formadas por militantes del NF (Forbes \& Stampton, 2015).

Con el incremento de adeptos, el NF se acercó a discográficas que habían producido letras que ensalzaban a Rudolf Hess, miembro del Partido Nazi, y a Robert Jay Mathew, que había dirigido The Order, un grupo terrorista estadounidense (Marchi \& Zúquete, 2016). También financió Blood and Honour (B\&H) que fue una asociación que organizaba conciertos racistas y anticomunistas en los que participaron los tres grupos que se convirtieron en el referente internacional del rock anticomunista: No Remorse, Brutal Attack y Skrewdiver. El vocalista de este último, Ian Stuart, sigue siendo el ídolo de muchos grupos porque revolucionó la forma convencional de hacer política ya que interactuaba con el público durante los espectáculos (Corte \& Edwards, 2008). El impacto de B\&H animó a que se fundara en España una delegación que convocaba espectáculos musicales que coincidían con la fecha del fallecimiento de Adolf Hitler o de Rudolf Hess donde se ensalzaba el antisemitismo, la xenofobia, así como la supremacía blanca (Movimiento contra la Intolerancia, 2008).

Las letras de las canciones incorporaron un discurso populista antiinmigración que retroalimentó un nacionalismo blanco y patriótico que rendía culto a la violencia (Brown, 2004) y que tuvieron cabida en una sociedad que estaba sufriendo los ecos de una desindustrialización promovida por la primera ministra Margaret Thatcher (Owen, 2012).

En este contexto sociopolítico, los skinheads adoptaran una estética proletaria y viril para oponerse a la feminización de la masculinidad que habían popularizado los hippies al dejarse el pelo largo. Además, se configuraron patrones identitarios que ensalzaron el poder blanco (Taylor \& Rambo, 2013) a través de melodías, canciones, imágenes propagandistas y violencia. La acción directa predominó en este sector y sus primeras víctimas fueron estudiantes de la London School of Economics and Political Science (Viñas i Gràcia, 2013), miembros del colectivo LGBTIQ (Martínez Belio \& Selepak, 2014) contra los que usaron la práctica queer bashing o fag bashing (Viñas i Gràcia, 2013) que se traduce como "golpear/aplastar a maricones" y, por último, contra las minorías raciales a través del paki-bashing (Brown, 2004) que, aunque hacía referencia a los paquistaníes porque era uno de los grupos foráneos que predominaban en el país, incluía a todos los inmigrantes. 
También crearon unos ritos escénicos que, acompañados con alcohol y con sustancias psicotrópicas, imitaban danzas guerreras. Las principales fueron el kicking knuckles (Blee, 1998) que consiste en golpear fuertemente los nudillos del compañero al son de la música, y el boot stomping (Windisch \& Simi, 2017) que es una danza semicoreográfica en la que se forma un círculo de entre diez y veinte personas que rotan hacia una dirección. Luego, uno de los integrantes del círculo, generalmente el más agresivo, se introducía en su interior y rotaba en dirección contraria al resto. Más tarde, todos se detenían y la persona que estaba en el centro se ponía en cuclillas para pisar fuertemente el suelo reiteradamente. Por último, gritaba enérgicamente para que el resto de compañeros le devolvieran el grito.

En lo que respecta al contenido de las letras, los compositores tuvieron como referentes obras de carácter antisemita como el panfleto Los Protocolos de los Sabios de Sion de 1903, el Mein Kampf de Adolf Hitler de 1925 y, por último, El Mito del Siglo XX de Alfred Rosenberg de 1930 (Shekhovtsov, 2012). Se hicieron alusiones constantes al acrónimo ZOG, es decir, Zionist Occupation Goverment o Gobierno de Ocupación Sionista (Martínez Belio \& Selepak, 2014, p.165) que es una teoría conspirativa que sostiene que Israel y la raza judía gobiernan el mundo. Este recurso da forma a varios eslóganes: Smash ZOG o "aplastar al ZOG", Kill ZOG o "matar al ZOG" y Death to ZOG o "muerte al ZOG". Finalmente, se denunció que todos los ciudadanos occidentales que luchaban por los derechos de las minorías étnicas, sexuales y por el feminismo eran unos traidores blancos.

En Italia la politización del rock tuvo lugar a partir de 1975 cuando el cantautor Leo Valeriano se aproximó a Ordine Nuovo, movimiento de extrema derecha violento que se había escindido del partido neofascista parlamentario, Movimiento Sociale Italiano (MSI), y cuando Carlos Venturio, miembro de la banda Amici del Vento, se afilió a la organización neofascista Círculo de Avanguardia Nazionale que estuvo formado por disidentes del MSI. En 1977 el MSI, al igual que hiciera el NF en Inglaterra, financió los Campos Hobbit o Campamentos Hobbit que fueron eventos musicales donde se desarrollaron talleres gráficos y conferencias políticas que disertaban sobre el pensamiento de teóricos fascistas y neofascistas de ámbito nacional (como Julius Evola, considerado el padre del neofascismo) e internacional (como el poeta nipón Yukio Mishima que había creado una escuadra juvenil conocida como tatenakai, cuya traducción es "sociedad del escudo", que tuvo por objeto salvaguardar las tradiciones japonesas) (Milá, 2016).

El estilo agresivo de los británicos caló en los cabeza rapadas españoles que obviaron el componente intelectual que pudieran tener los neofascistas italianos, por la acción directa violenta y un comportamiento vulgar. A pesar de las desavenencias entre ambas corrientes, la banda de folk neonazi Amici del Vento tocó en Madrid el 18 de diciembre de 1977, en un acto organizado por el partido de extrema derecha Fuerza Nueva para conmemorar a las víctimas del terrorismo de ETA. 


\section{Es por tu nación²: el RAC como difusión de odio en el Estado español}

Con la invasión del Oi!, del ska y del punk durante la Movida Madrileña, un movimiento contracultural impulsado por el Partido Socialista Obrero Español en 1982, en la Ciudad Condal se sentaron las bases de una nueva identidad juvenil que daría lugar al movimiento skinhead. En un primer momento, la banda punk Decibelios atrajo a adolescentes skinheads de entre dieciséis y diecisiete años. Aunque este grupo colaboró con las compañías discográficas antifascistas, antirracistas y feministas, tanto Manuela Caiani como Linda Parenti lo han incluido en una red neonazi que estaría conectada con los grupos de Facebook "GuipuzkoA88" y "Nueva Estirpe" (Caiani \& Parenti, 2011). Poco después, los skinheads neonazis adoptaron una estética e iconografía españolista que los diferenció de los punks.

En términos políticos, los cabeza-rapadas se acercaron a sectores juveniles de extrema derecha como Juntas Jóvenes, rama de Juntas Españolas, al Frente Nacional español de Blas Piñar o incluso al Círculo de Amigos de Europa (CEDADE). Estas formaciones rechazaron esta nueva identidad porque no querían verse involucrados con los actos violentos que provocaban. Según Jorge Mota, ex presidente de CEDADE, estos jóvenes banalizaban la política, y de acuerdo con Piñar habían sido financiados por la izquierda "para desprestigiar a la ultraderecha" (en Viñas i Gràcia, 2013, p. 523). No obstante, José Luis Rodríguez Jiménez defendió que este movimiento era una herramienta que empleaban los grupos de extrema derecha en determinados momentos para unos fines concretos (Rodríguez Jiménez, 1998). Finalmente, estos neonazis se aproximaron a asociaciones políticas extraparlamentarias como Bases Autónomas (BB.AA), Alianza Por la Unidad Nacional (que estuvo liderada por Ricardo Sáenz de Ynestrillas, hijo del General Ynestrillas, conocido por sus posturas golpistas; ver Sánchez Soler, 2003), Acción Radical o Democracia Nacional.

De estos, BB.AA rompió con las nociones de la ultraderecha conocidas hasta la fecha. BB.AA fue una organización madrileña creada en 1983 por José Antonio Aguilar y por Fernando Fernández Perdices. Este último regentaba una tienda donde había productos de grupos de RAC, objetos para hinchas de Ultra-Sur y accesorios neonazis (Salas, 2003, pp.64-65). La asociación fue proclive a la supremacía cultural, a la xenofobia, al racismo, al antisemitismo y quiso proyectar, según Xavier Casals, una especie de eugenesia social para acabar con el mestizaje. Tomó elementos nacionalsocialistas y anarquistas, pero no franquistas, pues calificó al 20-N como un episodio de vergüenza nacional (Casals i Meseguer, 1995). Esta asociación recibió fondos de los hermanos Carlos Rodrigo y Alfonso Ruiz

2 Título de una canción del grupo Klan. 
de Castro (Sánchez Soler, 2003) para crear el sindicato estudiantil universitario Dispar, combinación de las palabras Dios y Patria (Sánchez Soler, 2003). BB.AA se disolvió en 1990 porque no pudo integrarse en el ámbito parlamentario pues otros grupos de ultra derecha lo acusó de ensuciar la imagen de la derecha nacional y, por último, porque sus miembros estuvieron involucrados en los asesinatos de Ricardo Rodríguez García en Costa Polvoranca, quien habría mirado mal a los skinheads (Martínez Ahrens, 1995), y de la inmigrante Lucrecia Pérez (Nogueira, 1992).

Se ha hecho hincapié en el espacio político porque los músicos principales de estas bandas musicales militaron en muchas de ellas. En las siguientes páginas se analizarán las letras de las canciones de los tres grupos que sentaron las bases de una corriente musical que sigue vigente en la actualidad: División 250, Batallón de Castigo y Estirpe Imperial. Estas tres bandas pioneras dejaron de producir discos a inicios de los años 2000, pero se siguen reuniendo en ocasiones determinadas. Por último, se relatarán los contactos que tuvieron con discográficas nacionales e internacionales.

\section{División 250 (I99/-2000)}

Manuel Canduela fundó este grupo valenciano cuyo rótulo hace referencia a la unidad militar de infantería de la División Azul que luchó al lado de las potencias del eje durante la Segunda Guerra Mundial desde 1941 hasta 1943. Estuvo involucrado en varios proyectos de ultraderecha (Olmo, 2013): Acción Radical, Democracia Nacional y Plataforma $2000^{3}$.

El grupo estuvo en contacto con miembros de extrema derecha internacional puesto que su disco "Sangre de Conquistadores" de 1994 fue producido por la discográfica gala Rebelles Européens que fue creada por Bodilis Gael, antiguo militante del NF francés y miembro de la banda Brutal Combat, y, en segundo lugar, por el sello discográfico italiano Tuono Records creado por Massimo Bellini, baterista de Peggior Amico, que produjo "Revuelta" en 1996. En lo que respecta a las compañías españolas, trabajó con Rata Ta-Ta-Tá, que fue la matriz de los subsellos Bicéfala Records y Güevo de la Selpiente Records, que produjeron pistas de grupos nacionales e internacionales.

División 250 compuso letras en castellano a excepción de las canciones "Mai dexarem que tornen", "la Nostra Terra" y el título de "Blau Division". La temática de sus canciones se puede clasificar en tres categorías: la histórica, la crítica a la democracia y el culto a violencia como resolución de conflictos. Con la primera se puede realizar una retrospectiva histórica que parte del mesolítico, ya que alabó la

3 Canduela estuvo en contacto con el dirigente heleno del partido Amanecer Dorado, Nikolaos Michaloliakos. 
proeza guerrera de los celtas e íberos (División 250, 1996b), así como a la deidad de la guerra íbera, Netón (División 250, 1994d). Del Medioevo, se remarcaron las gestas heroicas de los visigodos durante la Reconquista, de los templarios y especialmente el papel del rey Jaime I, apodado El Conquistador (División 250, 1994f), porque representó la lucha contra los musulmanes en la Península Ibérica y en Mallorca durante el siglo XIII. También aludió a la monarquía hispánica por su proyección paternalista al haber ejercido una misión civilizadora en América Latina llevando el catolicismo y el castellano. Otro tema central fue la visión imperial de Europa que el nacionalismo español había dibujado durante el reinado de Carlos V y de Felipe II y que influyó en el imaginario del grupo, como se observa en la canción "Imperium" (División 250, 1999c):

Europa fue patria de Carlos V.

Sus ejércitos dominaron el mundo.

La unión de los pueblos en Europa.

$(\ldots)$

Conquistado por la juventud.

Europa será un imperio.

Por él combates tú.

La sangre que hoy corre por tus venas.

No hace tanto que lo intentó.

Hacer Europa otra vez imperio.

Que la justicia reinara de nuevo.

Esta visión incluyó la creación de una Europa libre, blanca y socialista-nacional. La libertad se dibujó con dos recursos de la mitología germana: con el lobo, que se asoció con el wolfsangel del régimen nazi, y con el águila imperial, que recuerda al reichsalder (División 250, 1996c). Este grupo también incorporó el eslogan "sangre y honor" (División 250, 1999b) que fue la traducción del lema de las Juventudes Hitlerianas, Blut und Ehre, como símbolo identitario. Esto puede verse en la canción "Es por tu nación":

Tu orgullo, tu sangre, tu honor y tu nación, nuestra sangre, nuestro orgullo, nuestro honor, es por tu nación.

Antes de que sea demasiado tarde.

Los traidores nos están utilizando, pronto pagarán sus engaños.

Nuestro futuro está siendo comprado, nuestra raza la han subestimado, no es cuestión de dinero y posición, es por mi tierra y la revolución. 
En lo que respecta a la crítica al régimen democrático, se culpó al sistema de haber asesinado a Rudolf Hess, que devino su icono (División 250, 1994e) y los miembros se acogieron al ninismo, es decir, defendieron que no eran ni de izquierdas ni de derechas, pero la banda se declaró nacionalsocialista (División 250, 1994a), tomó como referente a Ramiro Ledesma Ramos (División 250, 1996e) e incluso añadió en sus estrofas el Sieg Heil hitleriano que se traduce como "Eterna Victoria" y fue usado con frecuencia por los políticos del Tercer Reich.

Para División 250, la democracia era un artificio que había creado el ZOG para beneficiar al Estado de Israel, para generar altas tasas de desempleo (División 250, 1994b), para propiciar la llegada de inmigrantes (División 250, 1994c) que fomentaban la prostitución y la venta de drogas, para impulsar la homosexualidad y para legalizar el aborto. Denunció las políticas abortistas que se habían aprobado durante la gestión de Felipe González porque atentaba contra los derechos humanos (División 250, 1996d). También criticó el mandato gubernamental de José María Aznar por promover políticas de privatización en detrimento de los derechos de la clase media (División 250, 1999a).

Por último, el culto a la violencia fue frecuente en las letras de sus canciones. Desde estas, se apelaba a que la auténtica revolución nacional debía comenzar en las aulas de secundaria (División 250, 1999d). Así, se involucró al receptor en una supuesta guerra psicológica como se reflejó en la canción "Alza la espada" (División 250, 1996a) o empleando frases como "queremos morir por ti" (División 250, 1996f).

Esta temática apareció en la iconografía. En la portada de "Sangre de Conquistadores", aparecen los cuatro integrantes del grupo montados a caballo, simulando que son los Jinetes del Apocalipsis, mientras ondean una bandera con la cruz gamada, símbolo neonazi reconocido internacionalmente. En "Revuelta", aparecen los componentes con una vestimenta obrera demandando violencia. Por último, en "Imperium", aparecen dibujados legionarios romanos.

Por último, División 250 estuvo relacionada con la banda italiana, Hyperborea junto con la que tocó en un acto de plataforma España 2000 (Salas, 2003). Participó con los valencianos de Klan en el concierto de Fallas de Valencia de 1992 y en el de Villarcayo de 1994. Uno de los artistas de Klan, Juan Ignacio Vega Peinado, militó en Acción Radical (AR) (Maestre, 2019), fue candidato por España 2000 y, actualmente, está relacionado con Vox. Klan, colaboró con la discográfica Rata Ta-Ta-Tá y con su subsello, El Güevo de la Selpiente Record. Sus letras se compusieron en castellano, pero versionaron dos canciones alemanas, "Es por tu nación” (Klan, 1999a) y "Skinhead Por Siempre!” (Klan, 1999b) de los neonazis Böhse Onkelz, cuya traducción sería "tíoz maloz". En sus canciones se hizo alusión a ciertos episodios históricos de la Reconquista, ensalzaron la figura de Rodrigo 
Díaz de Vivar o Cid Campeador y la de Isabel "la Católica" (Klan, 1993b) e incorporaron el lema falangista ¡Arriba España! (Klan, 1993c). Por último, como División 250, glorificó la guerra a través de la mitología celta e identificó al dios Neto con los guerreros skinheads (Klan, 1993a).

\section{Estirpe Imperial (199/-2009)}

Este grupo madrileño se ha autodefinido en su cuenta oficial de Twitter como una banda de rock. Colaboró con el sello discográfico Rata Ta-Ta-Tá y sus letras están escritas en castellano y en inglés. Al igual que División 250, el grupo destacó los episodios de las cruzadas (Estirpe Imperial, 1993) para realizar un símil entre el cruzado y el skinhead al que denominó "guerrero de la noche" (Estirpe Imperial, 1995) porque debía combatir contra los peligros que acechaban la ciudad.

Por otro lado, compuso una canción en honor al apóstol Santiago cuando, de acuerdo con la mística cristiana, descendió del cielo para guiar a los cristianos en la lucha contra el moro (Estirpe Imperial, 1997c). También exaltó figuras del siglo de oro como Miguel de Cervantes, Bartolomé Esteban Murillo (Estirpe Imperial, 1997d) o Francisco de Quevedo, de quien versionó Miré los muros de la Patria Mía que reflejó la decadencia de la monarquía católica (Estirpe Imperial, 2007).

Se puso énfasis en el culto a la violencia y se mitificó a los combatientes que habían muerto por España con expresiones como "con el polvo de las tumbas teñido con la sangre de los muertos" (Estirpe Imperial, 1997a). Por ello, no es extraño que ensalzaran episodios nacionales que había mitificado el nacionalismo español como la Batalla de Covadonga o las Navas de Tolosa entre otras. Las letras, también, incitaron a la juventud a ingerir bebidas alcohólicas (Estirpe Imperial, 1999a) para que les sirviera de aliciente en esa lucha contra la inmigración y contra la corrupción (Estirpe Imperial, 1999b).

Otorgó un papel bélico al skinhead al que se le encomendó la tarea de construir una Europa blanca (Estirpe Imperial, 2000). Así, fue el primer grupo RAC español que incorporó la metáfora de las catorce palabras (Estirpe Imperial, 1997b), que fue una expresión que acuñó el estadounidense David Lane donde sintetizaba el principio de la supremacía blanca con el eslogan "debemos asegurar la existencia de nuestro pueblo y un futuro para los niños blancos"4. Estirpe Imperial fue proclive al nazismo y compuso una melodía titulada "Wolfgang's War", en honor Wolfgang Fürstner, militar de la Wehrmacht. Por último, versionó la canción “iHeil Dier!” de la banda alemana Landser, que fue clasificada por el Tribunal Federal de Justicia como una organización criminal al plasmar que su nación se

4 En inglés originalmente: "we must secure the existence of our people and a future for white children". 
erigía sobre los principios del völkisch nacionalsocialista (Elverich, Glaser y Schlimbach, 2009).

Para concluir, Estirpe Imperial estuvo en contacto con grupos RAC extranjeros como el portugués Oifensiva o con el italiano Sumbu Brothers con los que coincidió en un concierto en San Sebastián de los Reyes (Martin, 20013). Después de este evento, unos jóvenes agredieron violentamente a dos senegaleses. Finalmente, Estirpe Imperial colaboró con la compañía lusa, Raven's Call que había producido pistas del grupo racista sueco Ultima Thule, así como también del británico No Remorse.

Estos elementos neonazis y supremacistas fueron adoptados por el grupo vigitano, Torquemada 1488, creado en 1998. Su nombre estuvo compuesto por el apellido Torquemada, en referencia al inquisidor castellano Tomás de Torquemada y, de otro lado, por las cuatro cifras 1488. El 14 representa las catorce palabras de David Lane, mientras que el 88 corresponde a la letra $h$ que, duplicada, forma la frase Heil Hitler! Esta banda, incorporó el lema sangre y honor (Torquemada 1488, 1998b) y el eslogan falangista, “'Arriba España!” (Torquemada 1488, 1998a) como símbolos de honor nacional. Por último, publicó, en 2018, el álbum "Brigadas Blanquiazules" que se popularizó como "Gradas de Sangre" o "El Imperio Contraataca". En su carátula apareció dibujado un Totenkopf, símbolo militar que se apropiaron los nazis, sobre una cruz gamada circunscrita en un círculo con los títulos Torquemada 1488 y Brigadas Blanquiazules, que fue un grupo hincha de fútbol que se hermanó con Ultra Sur y ambos exhibieron esvásticas, cruces gamadas e insignias Totenkopf (Público, 2014).

\section{Batallón de Castigo ( 199 I)}

Eduardo Clavero creó esta banda en la prisión de Alcalá-Meco. Al igual que los líderes de División 250 y de Estirpe Imperial, militó en Alianza Nacional, de cariz nacionalsocialista y antisemita, de la que adoptó varios recursos. Tomó como icono al rey Sisebuto que gobernó en el siglo VII e inició una persecución que afectó a los judíos de la Península Ibérica (Caiani \& Parenti, 2011). Alianza Nacional se presentó como un movimiento nacionalista español, heredero de la tradición celtibera romana visigoda cristiana e hispánica, así como también de los fascismos europeos y, por ende, revolucionario (Alianza Nacional, 2006). Su lema Nación, Raza y Socialismo estuvo presente en el contenido de sus letras por lo que no es de extrañar que se hiciera alusión a una supuesta raza española ni que se enfatizaran las hazañas del Cid Campeador al usar expresiones como "que su sangre riegue el suelo de nuestra nación” (Batallón de Castigo, 1999).

Estirpe Imperial vertebró un discurso antisemita en torno al ZOG denunciando que los judíos, a los que se denominó "pueblo elegido por sí mismo”, habían 
manipulado la democracia (Batallón de Castigo, 2004a) para filtrar paulatinamente el comunismo (Batallón de Castigo, 2004b). Para Batallón de Castigo, la democracia, en tanto que régimen corrupto, había garantizado una sobreprotección a los inmigrantes, mientras que los ciudadanos autóctonos tenían que afrontar condiciones precarias (Batallón de Castigo, 1998), como se aprecia en la canción "Democracia":

Nos imponéis idiomas.

Que apenas habláis vosotros.

Nos prohibís nuestras banderas.

Símbolos de gloria.

Nos quitáis nuestro trabajo.

Para dárselo a extranjeros.

(...)

Democracia: mierda.

Mierda: democracia.

Democracia: mierda.

Sangre y fuego os merecéis.

Putos demócratas de mierda.

No nos vamos a detener.

Os declaramos la guerra.

Al igual que para los otros grupos, se concedió a los skinheads un carácter casi mesiánico al equipararlos con grandes combatientes que debían devolver la grandeza y la libertad a nuestra tierra. En este mensaje, la libertad representó la unidad de la raza española y estuvo asociada con la unión del hombre y del lobo, wosangel (Batallón de Castigo, 1998). La violencia se materializó entre los skinheads que escuchaban esta clase de música al igual que en el caso británico y los principales objetivos fueron las capas sociales más desfavorecidas, entre los que cabe destacar a vagabundos, marginados sociales, drogadictos, prostitutas, transexuales, homosexuales y travestidos. A pesar del elevado número de ataques violentos que se han registrado, hay estudios sociológicos que han demostrado que una parte sustancial de esta violencia fue tipificada como ritualizada, es decir, que estos adolescentes usaron una retórica agresiva más que la acción directa (Viñas i Gràcia, 2013). A pesar de ello, la violencia directa sigue siendo una realidad latente entre los miembros de esta cultura juvenil.

\section{Grupos menores}

La lista de grupos de rock neonazis españoles es bastante extensa, por eso se enumerarán los grupos que tuvieron contacto con la discográfica Rata Ta-Ta-Tá y con sus subsellos discográficos porque se relacionaron con los integrantes de la banda de la primera generación del RAC. En primer lugar, cabe destacar a la ban- 
da sevillana Primera Línea (Primera Línea, 1996), creada en 1995 y que, posteriormente, modificó su nombre por el de Ofensiva 88 (Salas, 2003). En segundo lugar, Céltica fue fundada por miembros de Estirpe Imperial y de Batallón de Castigo en 1998, y ensalzó los valores de la patria por la que merecería la pena morir y luchar. Además, consideró que las tradiciones, los valores y la cultura nacional estaban en declive ante la llegada masiva de los inmigrantes. Otros grupos efímeros fueron el valenciano Brigada 1238 (Brigada 1238, 2007), que debió su nombre a las capitulaciones de Valencia cuando el rey Jaime I expulsó a los musulmanes de la actual comunidad autónoma, Brigada Totenkopf (Brigada Totenkopf, 2006) y Al Filo de la Cuchilla, que estuvo formado por integrantes de Estirpe Imperial.

A nivel internacional, Rata Ta-Ta-Tá produjo el álbum "Blood and Soil" de los checos Buldok en 1999. Ese mismo año produjeron "La Isla de la Memoria", de los italianos Hyperborea. También colaboró con los portugueses de Endovélico en "Censura" del 2002. Por último, grabó los discos de los polacos Konkwista 88, "Nacidos para la gloria "y "10 Years on the Front Line" en 2003.

Como se ha indicado, Rata Ta-Ta-Tá fue la matriz de El Güevo de la Selpiente Records que registró el álbum “„No Te Cortes!” de 7 Muelles, en el que se glorificó el Imperio Español, la Conquista de América (7 Muelles, 2000c), las batallas nacionales (7 Muelles, 2000a) e incluso se reprodujo el lema franquista "una, grande y libre" en tres estrofas (7 Muelles, 2000b). Este grupo estuvo formado por el vocalista de Estirpe Imperial y por el primer guitarrista de Batallón de Castigo.

El grupo 14 Palabras, introdujo por primera vez en la escena española elementos de la mitología nórdica con los dioses Tyr (14 Palabras, 2000d), deidad de la guerra y Odín (14 Palabras, 2000b), dios principal del panteón nórdico. También ensalzó la figura de Ian Stuart al que identificaron como el creador del "ejército Blood and Honour" (14 Palabras, 2000c). También abogó por una Revolución Aria en perjuicio de la sociedad multirracial (14 Palabras, 2000e) y tuvo presente a los británicos de No Remorse cuando tradujo la versión "Armada Europa" (14 Palabras, 2000a), que fue un canto para derrotar a los rojos. Por otro lado, Toletvm no aportó nada nuevo al contenido de las canciones a excepción de una crítica al terrorismo nacionalista de ETA (Toletvm, 2001):

Nos intentáis quitar nuestra tierra

matando a nuestra gente

escudándoos en un pasado

que nunca tuvisteis diferente

no sabéis lo que estáis haciendo

nos estáis enfureciendo;

ya os tocará el turno de caer uno por uno

$\mathrm{Y}$ pagareis los asesinatos 
de las familias que habéis destrozado

Para concluir, un informe Raxen ha recogido varios grupos de rock anticomunista, pero hay una errata: Hyperborea, surgió en Italia no en España (Movimiento contra la Intolerancia, 2008). Estos conciertos, hasta la llegada de las redes sociales, se anunciaban en la revista Respuesta Sonora (Salas, 2003). Actualmente, muchos de estos conciertos se celebran en la clandestinidad porque incitan al odio, e incluso se ha condenado a los vocalistas de Batallón de Castigo y de Más que Palabras por estimular violencia (Mateo, 2011). A pesar de ello, estos eventos se celebran ya que en 2019 dos grupos neonazis, Iberian Wolves y Brigada Totenkoopf, actuaron en la Sala Caracol de Madrid (Martiarena, 2019).

\section{Consideraciones Finales}

La música RAC fue una herramienta política que sirvió a la extrema derecha para reclutar a jóvenes violentos procedentes de entornos disfuncionales. Esta estrategia surgió a finales de la década de 1960 en Inglaterra, a manos del National Front, y a mediados de la década de 1970 se plasmó en los eventos artísticos italianos conocidos como Campos Hobbit que fueron financiados por la primera fuerza política de este signo ideológico que consiguió representación parlamentaria, Movimento Sociale Italiano. Ambas experiencias exportaron música rock anticomunista y neonazi a escala internacional que caló en una juventud poco informada ideológicamente que adoptó la violencia como único método resolutivo de conflictos.

En el caso de España, esta nueva cultura juvenil skinhead se infiltró con la Movida Madrileña y se desarrolló en tres epicentros, Barcelona, Madrid y Valencia. Estos jóvenes, lejos de aglutinarse en agrupaciones de extrema derecha parlamentarias apostaron por otros movimientos políticos que rompieron con los postulados ideológicos de la extrema derecha nacional al acentuar el culto a la violencia. Estas bandas fueron proclives al nazismo, al antisemitismo, al anticomunismo, así como también se proclamaron defensores de una mística nacional españolista que, con sus letras, incitaban a emplear una guerra contra el otro. En estas páginas se han analizado las bandas de la primera generación y otros grupos menores que, bebiendo de las tres bandas pioneras, División 250, Estirpe Imperial y Batallón de Castigo, modificaron la música RAC a finales de los años noventa al añadir elementos procedentes de la mitología nórdica.

Con todo, la finalidad de este artículo ha sido arrojar un nuevo enfoque en el campo de los estudios culturales analizando las canciones de bandas neonazis que adoctrinaron a una juventud con hechos falsos y una perspectiva histórica politizada. 
Epistemus - volumen 9 - número 1 (Julio de 2021)

DOI: https://doi.org/10.24215/18530494e025

\section{Referencias}

7 Muelles. (2000a). Hoy como ayer [canción]. En ¡No te cortes! El Güevo de la Selpiente Records.

7 Muelles. (2000b). Nuestra España [canción]. En ¡No te cortes! El Güevo de la Selpiente Records.

7 Muelles. (2000c). Volverá [canción]. En ¡No te cortes! El Güevo de la Selpiente Records.

14 Palabras. (2000a). Armada Europa [canción]. En Esperanza. El Güevo de la Selpiente Records.

14 Palabras. (2000b). Hijo de Odín [canción]. En Esperanza. El Güevo de la Selpiente Records.

14 Palabras. (2000c). Ian Stuart [canción]. En Esperanza. El Güevo de la Selpiente Records.

14 Palabras. (2000d). Nuevo amanecer [canción]. En Esperanza. El Güevo de la Selpiente Records.

14 Palabras. (2000e). Orgullo Nacional [canción]. En Esperanza. El Güevo de la Selpiente Records.

Alianza Nacional (2006, 30 de abril). Acta del congreso nacional de militantes de carácter extraordinario. https://web.archive.org/web/20080908082841/http://www.alianzanacional. org/Descargas/Acta_del_Congreso_de_Refundacion.pdf

Batallón de Castigo. (1998). Contra la democracia [canción]. En ¡Caña de España! Rata Ta-Ta-Tá.

Batallón de Castigo. (1999).Campeador [canción]. En ¡Desperta Ferro! Rata Ta-Ta-Tá. Batallón de Castigo. (2004a). Pueblo elegido [canción]. En Akelarre. Rata Ta-TaTá.

Batallón de Castigo. (2004b). Realidad [canción]. En Akelarre. Rata Ta-Ta-Tá.

Blee, K. M. (1998). White-Knuckle Research: Emotional Dynamics in Fieldwork with Racist Activists. Qualitative Sociology, 21(4), 381-399.

Brigada 1238. (2007). Siglos de Gloria [CD]. Rata Ta-Ta-Tá.

Brigada Totenkopf. (2006). Avanz̧ado [CD]. Rata Ta-Ta-Tá. 
Brown, T. S. (2004). Subcultures, Pop Music and Politics: Skinheads and "Nazi Rock" in England and Germany. Journal of Social History, 38(1), 157-178. https:/ doi. org/10.1353/jsh.2004.0079

Buldok. (1999). Blood and soil [CD]. Rata Ta-Ta-Tá.

Caiani, M. \& Parenti, L. (2011). The Spanish extreme right and the Internet. Análise Social, 46(201), 719-740.

Camus, J-Y \& Lebourg, N. (2020). Las extremas derechas en Europa. Nacionalismo, populismo y xenofobia. Madrid: Clave Intelectual.

Casals i Meseguer, X. (1995). Neonazis en España: de las audiciones wagnerianas a los skinheads (1966-1995). Grijalbo.

Corte, U. \& Edwards, B. (2008). White Power Music and the Mobilization of Racist Social Movements. Music and Arts in Action. 1(1), 4-20.

División 250. (1994a). Cabezas rapadas [canción]. En Sangre de Conquistadores. Rebelles Européens.

División 250. (1994b). Democracia [canción]. En Sangre de Conquistadores. Rebelles Européens.

División 250. (1994c). Eh! [canción]. En Sangre de Conquistadores. Rebelles Européens.

División 250. (1994d). Hijos de Netón [canción]. En Sangre de Conquistadores. Rebelles Européens.

División 250. (1994e). In Memoriam [canción]. En Sangre de Conquistadores. Rebelles Européens.

División 250. (1994f). Mai dexarem que tornen [canción]. En Sangre de Conquistadores. Rebelles Européens.

División 250. (1996a). Alza la Espada [canción]. En Revuelta. Rata Ta-Ta-Tá.

División 250. (1996b). Furia inmortal [canción]. En Revuelta. Rata Ta-Ta-Tá.

División 250. (1996c). La nostra terra [canción]. En Revuelta. Rata Ta-Ta-Tá.

División 250. (1996d). No gracias [canción]. En Revuelta. Rata Ta-Ta-Tá.

División 250. (1996e). Pólvora y Sangre [canción]. En Revuelta. Rata Ta-Ta-Tá.

División 250. (1996f). Revuelta [canción]. En Revuelta. Rata Ta-Ta-Tá.

División 250. (1999a). Aznarakagar [canción]. En Imperivm. Ratata Ta-Ta-Tá.

División 250. (1999b). Es por tu nación [canción]. En Imperivm. Ratata Ta-Ta-Tá. 
División 250. (1999c). Imperivm [canción]. En Imperivm. Ratata Ta-Ta-Tá.

División 250. (1999d). Rebelión en las aulas [canción]. En Imperivm. Ratata Ta-Ta-Tá.

Elverich, G., Glaser, M. \& Schlimbach, T. (2009). Rechtsextreme Musik Ibre Funktionen für jugendliche Hörer/innen und Antworten der pädagogischen Praxis. Deutsches Jugendinstitut e. V., Außenstelle Halle.

Estirpe Imperial. (1993). La vuela del cruzado [canción]. En Estirpe Imperial. Rata Ta-TaTá.

Estirpe Imperial. (1995). Guerrero de la Noche [canción]. En Herederos de una Historia. Rata Ta-Ta-Tá.

Estirpe Imperial. (1997a). Esta es mi patria [canción]. En Himnos de Gloria. Rata Ta-TaTá.

Estirpe Imperial. (1997b). Hijo del Trueno [canción]. En Himnos de Gloria. Rata Ta-TaTá.

Estirpe Imperial. (1997c). Salutación a la bandera [canción]. En Himnos de Gloria. Rata Ta-Ta-Tá.

Estirpe Imperial. (1997d). Vieja Europa [canción]. En Himnos de Gloria. Rata Ta-TaTá.

Estirpe Imperial. (1999a). Iremos a un bar [canción]. En Una Grande Fuerte. Rata Ta-TaTá.

Estirpe Imperial. (1999b). Rebelión [canción]. En Una Grande Fuerte. Rata Ta-Ta-Tá.

Estirpe Imperial. (2000). Hacia la revolución [canción]. En Seguimos vivos. Rata Ta-TaTá.

Estirpe Imperial. (2007). Miré los Muros [canción]. En Sin Miedo. Rata Ta-Ta-Tá.

Forbes, R. \& Stampton, E. (2015). The White Nationalist Skinhead Movement: UK \& USA, 1979-1993. Feral House.

Klan. (1993a). Hordas Celtíberas [canción]. En Hordas Celtíberas. Rata Ta-Ta-Tá.

Klan. (1993b). Revolucionario español [canción]. En Hordas Celtíberas. Rata Ta-Ta-Tá.

Klan. (1993c). Un recuerdo de gloria [canción]. En Hordas Celtíberas. Rata Ta-Ta-Tá.

Klan. (1999a). Es por tu Nación [canción]. En Es por tu Nación. El Güevo de la Selpiente Record. 
Klan. (1999b). Skinhead por siempre [canción]. En Es por tu Nación. El Güevo de la Selpiente Record.

Maestre, A. (2019, 25 de marzo). Un militante de Vox Toledo fue un neonazi condenado por una brutal agresión que dejó con un 20\% de discapacidad a un profesor de la Universidad de Valencia. La Marea. https://www.lamarea.com/2019/03/25/jose-ignacio-vega-peinado-antesde-pasarse-a-vox-fue-candidato-de-espana-2000-y-miembro-de-la-organizacionneonazi-accion-radical/

Marchi, R. \& Zúquete, J. P. (2016). The Other Side of Protest Music: the extreme right and skinhead culture in democratic Portugal (1974-2015). Journalism, Media and Cultural Studies Journal, 9, 48-69. https://doi.org/10.18573/j.2016.10042

Martiarena, A. (2019, 9 de diciembre). La Sala Caracol se disculpa por celebrar un concierto de extrema derecha. La Vanguardia. https://www.lavanguardia.com/local/ma$\mathrm{drid} / 20191209 / 472127641235 /$ sala-caracol-conciertos-disculpas-grupos-extremaderecha-madrid.html

Martínez Ahrens, J (1995, 26 de mayo). Tres neonazis detenidos por el asesinato de Costa Polvoranca. El País. https://elpais.com/diario/1995/05/26/madrid/801487454_850215. html

Martínez Belio, A. \& Selepak, A. (2014). The sound of hate: exploring the use of hatecore song lyrics as a recruiting strategy by the White Power Movement. Intercom: Revista Brasileira de Ciências da Comunicação, 37(2), 153-175. https:/ /doi. org/10.1590/1809-584420147

Mateo, J. (2011, 8 de noviembre). El fiscal pide hasta 11 años de cárcel para diez miembros de dos grupos musicales neonazis. El Digital. https://eldiadigital.es/art/236546/el-fiscal-pidehasta-11-anos-de-carcel-para-diez-miembros-de-dos-grupos-musicales-neonazis

Milá, E. (2007). Neofascismo y alternativa (1945-1980). Las ideologías del neofascismo italiano y los Campos Hobbit. Revista de Historia del Fascismo, 26.

Movimiento contra la Intolerancia (2008). Informe Raxen. Racismo, Xenofobia, Antisemitismo, Islamofobia, Neofascismo, Homofobia y otras manifestaciones de Intolerancia a través de los hechos: El peligro de la Xenofobia y de la Violencia Ultra. http:/ / www.movimientocontralaintolerancia.com/html/raxen/raxen.asp

Nogueira, C. (1992, 20 de noviembre). Detenidos cuatro neonazis por "pintadas" favorables al asesinato de la dominicana. El País. https:/ / elpais.com/diario/1992/11/20/ espana/722214019_850215.html [Fecha de consulta: 05/VIII/2020]

Olmo, J. M. (2013, 14 de septiembre). Los ultras de Blanquerna, al habla con Amanecer Dorado para copiar su éxito. El Confidencial. https://www.elconfidencial.com/ espana/2013-09-14/los-ultras-de-blanquerna-al-habla-con-amanecer-dorado-paracopiar-su-exito_28414/ 
Primera Línea. (1996). España. „iDespierta Ya!! [CD]. Rata Ta-Ta-Tá.

Público. (2014, 30 de noviembre). Los ultras del fútbol se hermanan para combatir a grupos rivales. Público. https://www.publico.es/politica/ultras-del-futbol-hermanan-combatir. html

Salas, A. (2003). Diario de un Skin: un topo en el movimiento neonazi español. Círculo de lectores.

Sánchez Soler, M. (2003). Simplemente fascistas: articulos y ensayos sobre la violencia skinhead neonazi en España: 1996-2002. Alicante, Biblioteca Virtual Miguel de Cervantes.

Rodríguez Jiménez, J. L. (1998). La extrema derecha española del siglo XX. Alianza.

Shekhovtsov. A. (2012). European Far-Right Music and Its Enemies. En R. Wodak \& J. E. Richardson (eds.), Analyzing Fascist Discourse: European Fascism in Talk and Text (pp. 277-296). Routledge.

Taylor, M. \& Rambo, C. (2013). White Shame, White Pride: Emotional Cultures, Feeling Rules, and Emotion Exemplars in White Supremacist Movement Music. International Journal of Crime, Criminal Justice and Law, 8(1-2), 119-146.

Toletvm. (2001). Vascongadas por España [canción]. En Un Nuevo Orden para La Vieja Europa. El Güevo De La Selpiente Records.

Torquemada 1488. (1998a). España [canción]. En A degüello. Rata Ta-Ta-Tá.

Torquemada 1488. (1998b). Guerrero Skinhead [canción]. En A degüello. Rata Ta-TaTá.

Viñas i Gràcia, C. (2013). "Skinheads" a Espanya: Orígens, implantació i dinàmiques internes (1980-2010) [tesis de doctorado, Universitat de Barcelona]. Tesis Doctorals en Xarxa. http://hdl.handle.net/10803/108951

Windisch, S. \& Simi, P. (2017). Neo-Nazi Music Subculture. En S. E. Brown (ed.), Handbook of Deviance (pp. 111-121). Routledge. 